\title{
PELATIHAN GOOGLE SUITE TERHADAP DEWAN PAROKI KLATEN DAN PENGUKURAN TINGKAT PENERIMAAN TEKNOLOGINYA
}

\author{
Lukas Chrisantyo $^{1^{*}}$, Yuan Lukito ${ }^{2}$, dan Antonius Rachmat Chrismanto ${ }^{3}$ \\ 1,2,3 Program Studi Informatika, Universitas Kristen Duta Wacana \\ Jalan Dr. Wahidin Sudirohusodo 5-25 Yogyakarta \\ Email: 1lukaschris@staff.ukdw.ac.id; 2yuan@staff.ukdw.ac.id; 3anton@staff.ukdw.ac.id \\ *Penulis korespondensi
}

\begin{abstract}
Abstrak: Mempersiapkan daya saing masyarakat dalam industri era 4,0 dari generasi imigran digital memiliki tantangan tersendiri. Dewan Paroki Santa Maria Assumpta Klaten adalah contoh dari sebuah komunitas yang sebagian besar diisi oleh orang yang lahir sebelum generasi Milenium, atau sebelum 1980. Tugas kerja dan pelayanan dewan paroki sendiri memerlukan banyak bantuan teknologi dalam mempersiapkan, mengelola dan melaporkan program pastoral. Google Suite dipilih sebagai teknologi yang diharapkan dapat membantu pekerjaan dewan paroki. Pelatihan Google Suite disediakan dalam empat sesi, masing-masing berfokus pada pembuatan akun, penyimpanan data dan manajemen file, kolaborasi pengeditan file, koordinasi acara bersama, dan pembuatan formulir online. Pada akhir pelatihan, kuesioner dikerahkan untuk mengukur tingkat penerimaan teknologi. Dari perhitungan yang dibuat, disimpulkan bahwa Dewan Paroki Santa Maria Assumpta Klaten memiliki niat baik untuk belajar Google suite dan menganggap bahwa aplikasi ini bermanfaat untuk kegiatan pelayanan gerejawi mereka.
\end{abstract}

Kata kunci: Google suite; pelatihan; penerimaan teknologi.

\begin{abstract}
Preparing competitiveness in the Industry 4.0 era towards the people from digital immigrant generation has its own challenges. The Parish Council of Santa Maria Assumpta Klaten is an example of a community that is mostly filled by people born before the millennial generation, or before 1980. The work and service assignments of the Parish Council itself require a lot of technological assistance in preparing, managing and reporting pastoral programs. Google Suite was chosen as a technology that is expected to help the work of the Parish Council. Google Suite training is provided in four sessions, each of which focuses on account creation, cloud storage and file management, file editing collaboration, coordination of shared events, and online form creation. At the end of the training, a questionnaire was deployed to measure the level of acceptance of the technology. From the calculations made, it was concluded that the Parish Council of Santa Maria Assumpta Klaten had good intentions to study Google Suite and considered that this application was beneficial for their ecclesiastical service activities.
\end{abstract}

Keywords: Google Suite; training; technology acceptance.

\section{PENDAHULUAN}

Dewan Paroki merupakan sekumpulan orang yang mengelola segala sendi kehidupan sebuah paroki. Paroki itu sendiri adalah suatu teritori lokal gereja Katolik yang terdiri dari beberapa wilayah/ stasi dan satu wilayah memiliki beberapa lingkungan yang dihuni oleh sekian ratus umat Katolik. Dewan Paroki dipimpin oleh Romo Kepala Paroki dan di bawahnya terdapat beberapa orang awam yang mengelola berbagai bidang pastoral dan pelayanan umat.

Seperti pada umumnya paroki-paroki di Indonesia terutama di kota hinterland, Dewan Paroki
Santa Maria Assumpta Klaten saat pengabdian ini dilaksanakan diisi oleh orang-orang dari generasi Baby Boomers dan generasi X. Generasi Baby Boomers adalah mereka yang dilahirkan pada kisaran tahun 1950-1960, dan generasi X adalah mereka yang dilahirkan pada kisaran tahun 1960-1980 (Biggs, 2007). Sedangkan mereka yang masuk geneasi milenial / Y (dilahirkan tahun 1980-2000) hanya ada dua orang.

Permasalahan yang ditemui adalah relatif rendahnya pemanfaatan teknologi informasi dalam mendukung koordinasi antar tim kerja maupun kepanitiaan. Selama ini teknologi yang paling banyak dipakai adalah aplikasi Office offline (Micro- 
soft Word, Excel dan Powerpoint) serta messenger WhatsApp untuk berkomunikasi dan berkirim file. Tentunya dengan hanya memanfaatkan aplikasi tersebut secara default belum mampu melakukan pekerjaan dengan tingkat efektivitas dan efisiensi yang tinggi, contohnya untuk berkolaborasi mengerjakan satu file bersama.

Google, Inc. melalui produknya Google Suite memberikan solusi yang mudah dan gratis bagi individu atau kelompok yang membutuhkan. Produk yang cukup umum dikenal adalah Google mail (Gmail), Google Drive, Google Calendar, Google Forms, Google Maps, Google Contacts dan masih banyak yang lainnya. Berdasarkan pengamatan secara intuitif, tidak banyak anggota Dewan Paroki yang secara optimal memanfaatkan produk Google Suite. Sementara kinerja tugas dan tanggung jawab mereka dapat lebih terselesaikan dengan efisien apabila dibantu dengan teknologi ini. Contoh kasus yang mudah ditemui antara lain sebagai berikut:

- Masih banyak yang menggunakan layanan email yang rentan kena hack,

- Masih banyak yang sudah membuka akun gmail karena disyaratkan oleh smartphone android, tetapi tidak mengingat passwordnya,

- Belum mampu berbagi file untuk disunting bersama secara kolaboratif

- Koordinasi acara masih menggunakan undangan melalui whatsapp yang rentan terlewatkan oleh karena banyaknya chat dan kebiasaan generasi baby boomers dan generasi $\mathrm{x}$ berbagi informasi yang kurang penting,

- Survey maupun kuisioner yang masih dilakukan secara manual, atau sudah secara online namun tidak banyak tanggapan karena bingung cara menggunakannya.

Kesulitan-kesulitan ini diharapkan akan banyak terbantu jika para pengurus Dewan Paroki mau dan mampu melibatkan teknologi dalam hal ini Google Suite. Untuk mewujudkan harapan tersebut, penulis melakukan pengabdian masyarakat dalam bentuk pelatihan Google Suite dan mengukur tingkat penerimaan teknologinya dengan kuisioner sederhana. Juga akan diteliti apakah ada pengaruh generasi yang mengisi kepengurusan Dewan Paroki terkait dengan penerimaan teknologi tersebut.

\section{METODE PELAKSANAAN}

Pengabdian masyarakat ini dilaksanakan dalam beberapa kegiatan:

i. Perancangan modul pelatihan disesuaikan dengan kebutuhan Dewan Paroki.

ii. Pelatihan Google Mail untuk menyiapkan account yang baik, mudah diingat dan aman. iii. Pelatihan Google Drive untuk membiasakan kolaborasi penyuntingan dokumen yang sama. Studi kasus penyuntingan teks panduan misa.

iv. Pelatihan Google Calendar untuk berkoordinasi dalam menyusun agenda bersama.

v. Pelatihan Google Forms untuk menghimpun data secara rapid dan valid.

vi. Evaluasi hasil pelatihan dan pelaporan kepada pihak pendukung pembiayaan pelatihan.

Perancangan modul pelatihan dilakukan oleh penulis, berdasarkan antarmuka Google Suite yang tayang pada periode Januari-Februari 2019. Besar kemungkinan ada perbaikan dan penambahan fitur lagi setelah itu. Terdapat empat buah modul yang sudah disiapkan.

Oleh karena kegiatan pengabdian ini bekerja sama dengan Bidang Penelitian dan Pengembangan Dewan Paroki Santa Maria Assumpta Klaten, maka untuk publikasi informasi pelatihan dibantu oleh tim bidang litbang. Publikasi dilakukan melalui pengumuman seusai misa, dan broadcast informasi melalui grup WhatsApp pengurus lingkungan.

Pelatihan dibagi menjadi dua batch: batch Maret dan Mei. Setiap batch terdiri dari empat pertemuan yang masing-masing berdurasi 120 menit. Jadwal pelatihan tercantum pada Tabel 1. Tim pengabdian memutuskan menjadwalkan menjadi dua batch dikarenakan ada evaluasi pelaksanaan pelatihan tahun sebelumnya (2018) dimana peminat pelatihan sangat banyak sehingga panitia kewalahan dari segi layanan teknis koneksi internet.

Batch Maret diikuti oleh tujuh peserta yang dirinci pada Tabel 2. Sedangkan batch Mei diikuti oleh 15 peserta yang juga dirinci pada Tabel 2 .

Tabel 1. Jadwal Pelatihan Google Suite

\begin{tabular}{cccc}
\hline Batch & Pertemuan & Waktu & Materi \\
\hline Maret & I & Minggu, 10 Maret 2019 & Google Mail \\
& II & Minggu, 17 Maret 2019 & Google Drive \\
& III & Minggu, 24 Maret 2019 & Google Calendar \\
& IV & Minggu, 31 Maret 2019 & Google Forms \\
\hline Mei & I & Jumat, 10 Mei 2019 & Google Mail \\
& II & Jumat, 17 Mei 2019 & Google Drive \\
& III & Jumat, 24 Mei 2019 & Google Calendar \\
& IV & Jumat, 31 Mei 2019 & Google Forms \\
\hline
\end{tabular}

Tabel 2. Profil Peserta Pelatihan

\begin{tabular}{lcc}
\hline Batch & Generasi & Jumlah (orang) \\
\hline Maret & Baby Boomers & 1 \\
& Gen X & 2 \\
& Gen Millennial/Y & 2 \\
& Gen Z & 2 \\
\hline Mei & Baby Boomers & 0 \\
& Gen X & 6 \\
& Gen Millennial/Y & 5 \\
& Gen Z & 4 \\
\hline
\end{tabular}


Pada sesi pertama, peserta berlatih untuk membuat akun Google baru, baik mereka yang sudah memiliki maupun yang belum. Peserta juga diberikan petunjuk bagaimana mengoptimalkan akun di PC maupun smartphone, dimulai dari memilih nama akun yang baik, menentukan password yang aman namun mudah diingat, mengkustomisasi mailbox, membuat sendiri signature line, dan berlatih saling berkirim email. Peserta juga dikenalkan dengan Google Contacts untuk mengelola alamat email dari relasi dan memberi label kelompok relasi yang sering dikirimi email. Suasana pelatihan dapat dilihat pada Gambar 1 dan Gambar 2.

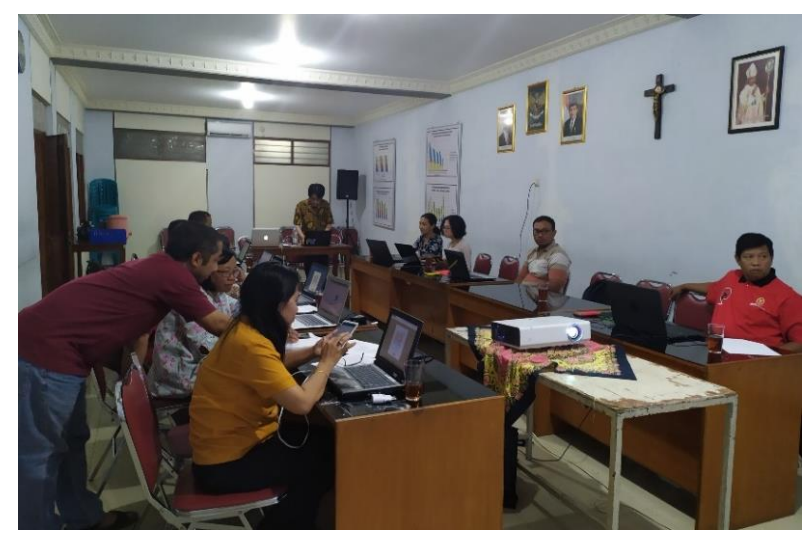

Gambar 1. Suasana Pelatihan Google Suite

Dari sesi pertama sudah terlihat perbedaan respon terhadap teknologi. Generasi Baby Boomers dan $\mathrm{X}$ yang mengikuti pelatihan cukup antusias dan rajin bertanya. Sedangkan Generasi Milennial dan $\mathrm{Z}$ cenderung mencoba sendiri sebisanya, mencari solusi sendiri apabila ada permasalahan, dan baru bertanya ketika benar-benar tidak menemukan solusi.

Pada sesi kedua, peserta diperkenalkan dengan Google Drive dan Google Backup \& Sync. Peserta berlatih untuk mengisi folder yang dibagi pakai bersama. Kemudian peserta diajak untuk latihan berkolaborasi membuat teks panduan misa menggunakan Google Document. Masing-masing peserta diberikan tugas untuk mengisi di bagian yang berbeda-beda dari panduan misa.

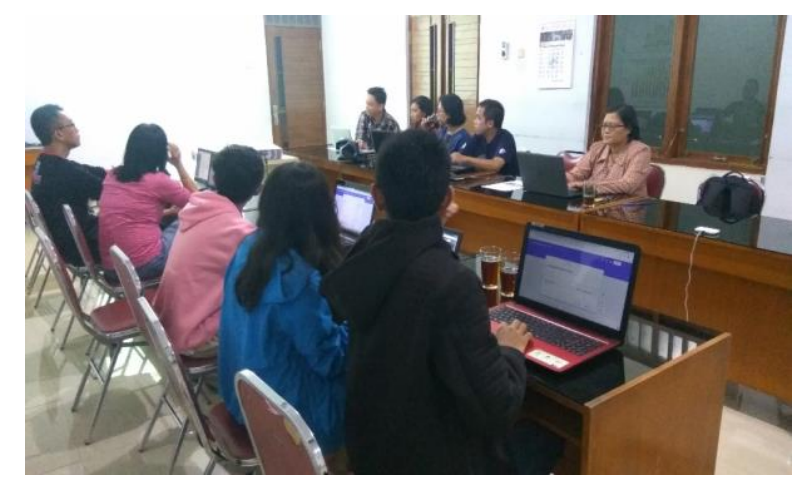

Gambar 2. Pelatihan dengan Materi Google Forms
Pada sesi ketiga, peserta diberikan materi Google Calendar. Peserta berlatih membuat acara dan mengundang peserta lainnya melalui email. Peserta yang diundang juga dibiasakan untuk menanggapi undangan sesuai dengan keputusan masing-masing. Bagian yang tersulit di sini adalah menggerakan kebiasaan/habit peserta untuk aktif menanggapi undangan. Kemudian peserta juga ditunjukkan bagaimana cara sinkronisasi undangan acara di kalender smartphone masing-masing.

Pada sesi keempat atau terakhir, peserta diajak untuk membuat formulir pendaftaran menggunakan Google Forms. Peserta juga diberi kesempatan untuk mencoba mengisi formulir buatan peserta yang lain. Kemudian peserta diperlihatkan cara untuk mengelola file response dalam bentuk spreadsheet.

Setelah sesi terakhir peserta diberikan survey untuk mengukur tingkat penerimaan teknologi Google Suite dengan framework Technology Acceptance Model (TAM). Teori TAM ini diusulkan oleh Fred Davis yang mampu menjelaskan perilaku pengguna terhadap teknologi (Davis, 1989). Teori ini didukung oleh berbagai penelitian yang dilakukan terhadap orang-orang yang diminta atau ditugaskan untuk menggunakan teknologi informasi tertentu seperti pada perpustakaan (Yuadi, 2009), penerapan e-class pada civitas akademika suatu universitas (Widiatmoko, Chrisantyo, \& Dewi, 2017) dan penelitian-penelitian lain.

TAM dikembangkan dari teori psikologis yang menjelaskan tentang perilaku pengguna komputer yang berlandaskan pada belief, attitude, intention dan user behavior relationship. (Setiawan, 2018). Tujuan model ini adalah untuk menjelaskan faktorfaktor dari perilaku pengguna terhadap penerimaan penggunaan teknologi. Model ini menempatkan faktor sikap (attitude) dari setiap perilaku pengguna dengan empat variabel:

1. Persepsi kemudahan (perceived ease of use)

2. Persepsi kegunaan (perceived usefulness)

3. Sikap penggunaan (attitude towards using)

4. Niat perilaku penggunaan (behavioral intention to use)

Keempat aspek tersebut dapat menjelaskan bahwa sikap para pengguna akan menentukan sikapnya terhadap penggunaan teknologi tersebut. Untuk mendapatkan Peserta diminta mengisi kuisioner dengan pertanyaan berikut terhadap aplikasi Gmail, Google Drive, Google Forms, Google Calendar dan Google Document:

A. Aspek Persepsi Kegunaan

1) Menggunakan aplikasi Google memungkinkan saya untuk menyelesaikan pekerjaan Dewan Paroki dengan lebih cepat (PU1)

2) Menggunakan aplikasi Google sangat penting untuk menyelesaikan pekerjaan saya di Dewan Paroki (PU2) 
3) Menggunakan aplikasi Google meningkatkan produktivitas saya di dalam pekerjaan Dewan Paroki (PU3)

4) Dengan menggunakan aplikasi Google urusan surat-menyurat jadi lebih cepat (PU4)

5) Dengan menggunakan aplikasi Google pengiriman file atau dokumen ke kerabat atau anggota Dewan Paroki lainnya semakin cepat (PU5)

6) Dengan menggunakan aplikasi Google saya dapat mengatur dan melihat jadwal kegiatan pelayanan saya di gereja lebih baik lagi (PU6)

7) Aplikasi Google sangat membantu saya mempermudah komunikasi dengan anggota dewan lainnya (PU7)

8) Dengan menggunakan aplikasi Google filefile atau dokumen penting saya dapat disimpan dengan aman (PU8)

9) Secara keseluruhan aplikasi Google sangat berguna dan membantu pekerjaan saya (PU9)

B. Aspek Persepsi Kemudahan

1) Aplikasi Google bagi saya mudah dipelajari untuk keperluan pekerjaan atau kegiatan pelayanan saya di gereja (PEOU1)

2) Mudah bagi saya untuk menjadi ahli dalam menggunakan aplikasi Google di dalam karya pelayanan saya di gereja (PEOU2)

3) Aplikasi Google sangat mempermudah saya dalam melakukan pengiriman file atau dokumen ke sesama anggota gereja lainnya (PEOU3)

4) Aplikasi Google mempermudah saya untuk berkomunikasi antar anggota gereja (PEOU4)

5) Aplikasi Google sangat mudah diakses melalui smartphone saya (PEOU5)

6) Kemudahan mencari petunjuk penggunaan pada aplikasi Google (PEOU6)

7) Aplikasi Google mudah diakses di mana saja dan kapan saja (PEOU7)

C. Aspek Sikap Dalam Menggunakan

1) Saya lebih menyukai menggunakan aplikasi Google pada saat membuat surat, form atau dokumen saya daripada dilakukan secara manual (ATU1)

2) Saya lebih suka mengirim dokumen, membagikan kuisioner atau membuat dokumen dengan sesama umat gereja saya melalui aplikasi Google daripada bertemu langsung (ATU2)

3) Saya lebih suka menyimpan file atau dokumen penting saya di aplikasi Google daripada di laptop, komputer atau hard disk eksternal (ATU3)

4) Saya lebih suka menggunakan aplikasi Google dalam mengingatkan atau mencatat kegiatan saya ke depan, daripada menggunakan buku tulis (ATU4)

5) Saya lebih suka melihat dokumen, surat, formulir, kalender atau foto melalui aplikasi Google daripada melihat dari hard disk lokal (ATU5)
6) Saya lebih suka melihat suatu file dalam bentuk softcopy yang disimpan dalam aplikasi Google daripada hardcopy (ATU6)

D. Aspek Niat Perilaku Penggunaan

1) Aplikasi Google memotivasi saya agar tetap menggunakannya dalam pekerjaan dan kegiatan saya di Dewan Paroki (BITU1)

2) Saya akan merekomendasikan aplikasi Google kepada anggota gereja atau kerabat saya yang lain (BITU2)

3) Saya ingin menggunakan aplikasi Google secara mandiri (BITU3)

4) Dalam melakukan kegiatan dan pekerjaan saya di Dewan Paroki, saya akan menggunakan aplikasi Google (BITU4)

E. Aspek Penggunaan dalam Sistem Sesungguhnya

1) Saya nyaman menggunakan aplikasi Google dalam melakukan pekerjaan dan kegiatan saya di gereja (AU1)

2) Saya mengandalkan aplikasi Google dalam melakukan pekerjaan atau kegiatan saya di gereja (AU2)

3) Saya mengerti dan memahami cara menggunakan aplikasi Google dalam melakukan kegiatan dan pekerjaan saya di gereja (AU3)

4) Saya akan terus menggunakan aplikasi Google secara rutin (AU4)

\section{HASIL DAN PEMBAHASAN}

Dari hasil kuisioner didapatkan nilai untuk PU, PEOU, ATU, BITU dan AU seperti tercantum pada Tabel 3 hingga Tabel 7.

Tabel 3. Hasil Perceived Usefulness (PU)

\begin{tabular}{cccccccccc}
\hline Peserta & PU1 & PU2 & PU3 & PU4 & PU5 & PU6 & PU7 & PU8 & PU9 \\
\hline 1 & 3 & 3 & 4 & 4 & 5 & 5 & 4 & 4 & 5 \\
2 & 3 & 4 & 4 & 4 & 4 & 4 & 4 & 4 & 4 \\
3 & 2 & 2 & 2 & 1 & 2 & 1 & 1 & 2 & 2 \\
4 & 4 & 4 & 4 & 4 & 4 & 3 & 3 & 3 & 6 \\
5 & 1 & 2 & 2 & 1 & 2 & 2 & 2 & 2 & 1 \\
6 & 1 & 2 & 2 & 2 & 2 & 2 & 1 & 3 & 2 \\
7 & 4 & 5 & 4 & 5 & 5 & 4 & 4 & 5 & 5 \\
8 & 4 & 4 & 4 & 3 & 3 & 4 & 4 & 4 & 4 \\
9 & 3 & 3 & 4 & 4 & 4 & 4 & 4 & 4 & 4 \\
10 & 3 & 3 & 4 & 4 & 4 & 4 & 3 & 4 & 4 \\
11 & 2 & 4 & 4 & 4 & 4 & 3 & 3 & 4 & 4 \\
12 & 4 & 4 & 4 & 3 & 4 & 3 & 3 & 4 & 5 \\
13 & 1 & 1 & 1 & 1 & 1 & 1 & 1 & 1 & 1 \\
14 & 3 & 3 & 3 & 3 & 3 & 3 & 3 & 3 & 3 \\
15 & 2 & 2 & 2 & 2 & 2 & 2 & 2 & 1 & 2 \\
\hline
\end{tabular}

Metode pendugaan parameter atau estimasi di dalam pengolahan hasil kuisioner ini menggunakan algoritma PLS (partial least square) pada software smartPLS 3. PLS adalah metode analisis yang cukup kuat dan efektif karena data yang diolah tidak harus berdistribusi normal multivariat. Bahkan indikator dengan skala data kategori, ordinal, interval sampai rasio dapat digunakan. Keunggulan lain adalah ukuran sampel yang tidak harus besar. Setelah data diolah maka didapatkan hasil path coefficients seperti pada Gambar 3. 
Tabel 4. Hasil Perceived Ease of Use (PEOU)

\begin{tabular}{cccccccc}
\hline Peserta & \multicolumn{7}{c}{ PEOU PEOU PEOU PEOU PEOU PEOU PEOU } \\
& $\mathbf{1}$ & $\mathbf{2}$ & $\mathbf{3}$ & $\mathbf{4}$ & $\mathbf{5}$ & $\mathbf{6}$ & $\mathbf{7}$ \\
\hline 1 & 5 & 3 & 4 & 4 & 5 & 4 & 5 \\
2 & 4 & 4 & 4 & 4 & 4 & 4 & 4 \\
3 & 3 & 3 & 3 & 3 & 4 & 4 & 4 \\
4 & 5 & 3 & 5 & 5 & 5 & 5 & 5 \\
5 & 2 & 3 & 2 & 3 & 2 & 4 & 4 \\
6 & 2 & 2 & 2 & 2 & 3 & 2 & 3 \\
7 & 4 & 4 & 4 & 4 & 4 & 4 & 3 \\
8 & 4 & 4 & 4 & 4 & 5 & 5 & 5 \\
9 & 3 & 4 & 4 & 4 & 4 & 3 & 4 \\
10 & 4 & 4 & 4 & 3 & 4 & 3 & 4 \\
11 & 4 & 3 & 4 & 4 & 3 & 3 & 4 \\
12 & 4 & 3 & 4 & 4 & 4 & 4 & 5 \\
13 & 1 & 1 & 1 & 1 & 1 & 1 & 1 \\
14 & 3 & 3 & 3 & 3 & 3 & 3 & 3 \\
15 & 2 & 2 & 2 & 2 & 2 & 2 & 2 \\
\hline
\end{tabular}

Tabel 5. Hasil Attitude Toward Using (ATU)

\begin{tabular}{ccccccc}
\hline Peserta & ATU1 & ATU2 & ATU3 & ATU4 & ATU5 & ATU6 \\
\hline 1 & 4 & 4 & 4 & 4 & 5 & 4 \\
2 & 4 & 4 & 5 & 5 & 5 & 3 \\
3 & 3 & 3 & 3 & 3 & 3 & 3 \\
4 & 5 & 5 & 5 & 4 & 5 & 5 \\
5 & 3 & 3 & 3 & 4 & 3 & 3 \\
6 & 2 & 3 & 2 & 4 & 4 & 4 \\
7 & 4 & 4 & 4 & 3 & 5 & 4 \\
8 & 5 & 4 & 4 & 5 & 4 & 4 \\
9 & 3 & 3 & 3 & 3 & 3 & 3 \\
10 & 3 & 3 & 3 & 3 & 3 & 3 \\
11 & 3 & 4 & 4 & 4 & 4 & 4 \\
12 & 3 & 4 & 4 & 3 & 4 & 4 \\
13 & 3 & 3 & 3 & 3 & 3 & 3 \\
14 & 3 & 3 & 3 & 3 & 3 & 3 \\
15 & 3 & 3 & 3 & 3 & 2 & 2 \\
\hline
\end{tabular}

Tabel 6. Hasil Behavioral Intention to Use (BITU)

\begin{tabular}{ccccc}
\hline Peserta & BITU1 & BITU2 & BITU3 & BITU4 \\
\hline 1 & 4 & 4 & 4 & 4 \\
2 & 5 & 5 & 5 & 5 \\
3 & 4 & 3 & 4 & 4 \\
4 & 5 & 4 & 5 & 3 \\
5 & 4 & 3 & 4 & 4 \\
6 & 4 & 4 & 4 & 1 \\
7 & 4 & 5 & 5 & 4 \\
8 & 5 & 5 & 5 & 4 \\
9 & 4 & 4 & 4 & 3 \\
10 & 4 & 4 & 4 & 4 \\
11 & 4 & 4 & 4 & 4 \\
12 & 5 & 5 & 5 & 5 \\
13 & 4 & 4 & 3 & 3 \\
14 & 3 & 3 & 3 & 3 \\
15 & 4 & 4 & 4 & 4
\end{tabular}

Tabel 7. Hasil Actual System Usage (AU)

\begin{tabular}{ccccc}
\hline Peserta & AU1 & AU2 & AU3 & AU4 \\
\hline 1 & 4 & 4 & 4 & 4 \\
2 & 5 & 4 & 4 & 4 \\
3 & 3 & 3 & 3 & 4 \\
4 & 4 & 4 & 4 & 4 \\
5 & 4 & 3 & 3 & 3 \\
6 & 4 & 4 & 4 & 4 \\
7 & 4 & 4 & 4 & 4 \\
8 & 5 & 4 & 5 & 4 \\
9 & 3 & 3 & 3 & 3 \\
10 & 4 & 4 & 4 & 4 \\
11 & 4 & 4 & 4 & 4 \\
12 & 5 & 5 & 5 & 5 \\
13 & 3 & 3 & 3 & 3 \\
14 & 3 & 3 & 3 & 3 \\
15 & 3 & 3 & 3 & 3 \\
\hline
\end{tabular}

Pengujian hipotesis dilakukan dengan melihat Output path coefficient

- Ho (hipotesis nihil): y1 = 0; artinya tidak terdapat pengaruh positif

- Ha (hipotesis alternatif) : $\mathrm{Y}^{1} \neq 0$; artinya terdapat pengaruh positif

Hasil:

1. Path Coefficients ATU (Definisi mengenai sikap) terhadap BITU (Niat perilaku penggunaan) adalah Ha dapat diterima, Hal ini dibuktikan dari besarnya nilai t statistik untuk ATU terhadap BITU di atas 2.228 yaitu sebesar 2.359.

2. Path Coefficients BITU (Niat perilaku penggunaan) terhadap AU (Penggunaan sistem sesungguhnya) adalah $\mathrm{Ha}$ dapat diterima, $\mathrm{Hal}$ ini dibuktikan dari besarnya nilai $\mathrm{t}$ statistik untuk BITU terhadap AU di atas 2.228 yaitu sebesar 10.052 .

3. Path Coefficients PEOU (Persepsi kemudahan) terhadap ATU (Definisi mengenai sikap) adalah Ha tidak dapat diterima, $\mathrm{Hal}$ ini dibuktikan dari besarnya nilai t statistik untuk PEOU terhadap ATU di bawah 2.228 yaitu sebesar 1.292.

4. Path Coefficients PEOU (Persepsi kemudahan) terhadap PU (Persepsi kegunaan) adalah Ha dapat diterima, Hal ini dibuktikan dari besarnya nilai t statistik untuk PEOU terhadap PU di atas 2.228 yaitu sebesar 16.063 .

5. Path Coefficients PU (Persepsi kegunaan) terhadap ATU(Definisi mengenai sikap) adalah Ha

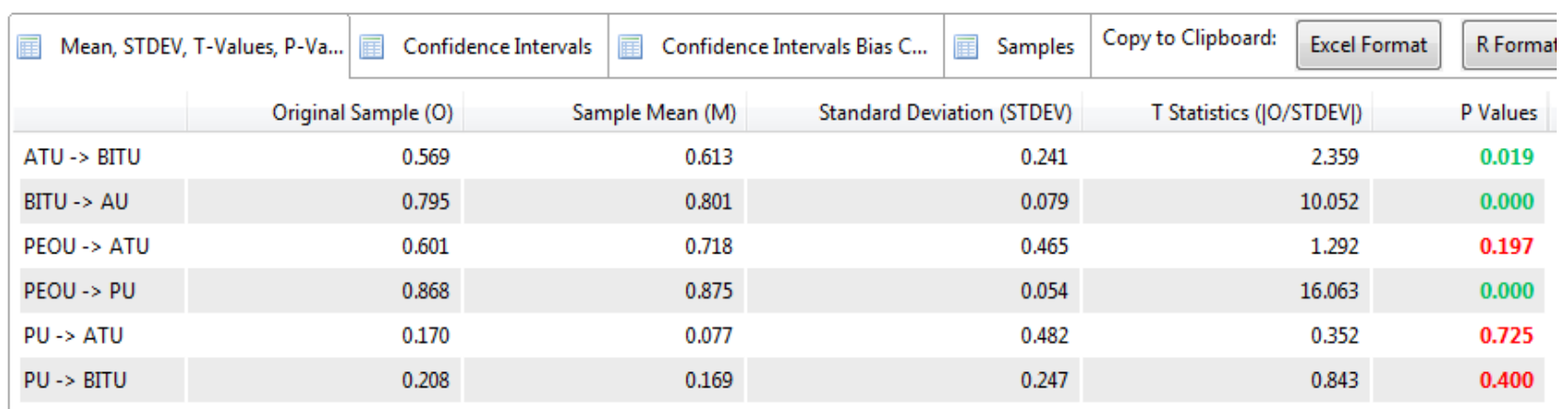

Gambar 3. Hasil Path Coefficients 
tidak dapat diterima, Hal ini dibuktikan dari besarnya nilai $\mathrm{t}$ statistik untuk PU terhadap ATU di bawah 2.228 yaitu sebesar 0.352 .

6. Path Coefficients PU (Persepsi kegunaan) terhadap BITU (Niat perilaku penggunaan) adalah Ha tidak dapat diterima, Hal ini dibuktikan dari besarnya nilai t statistik untuk PU terhadap BITU di bawah 2.228 yaitu sebesar 0.843 .

\section{KESIMPULAN}

Berdasarkan pengukuran TAM, disimpulkan bahwa definisi mengenai sikap berpengaruh signifikan terhadap niat perilaku penggunaan. Sedangkan niat perilaku penggunaan berpengaruh signifikan terhadap penggunaan sistem sesungguhnya. Persepsi kemudahan juga sangat berpengaruh terhadap persepsi kegunaan. Namun ditemukan juga bahwa persepsi kemudahan dan persepsi kegunaan tidak berpengaruh terhadap definisi mengenai sikap dan niat perilaku penggunaan teknologi Google Suite.

Sehubungan dengan hal tersebut, hendaknya pihak Dewan Paroki dapat lebih memperbanyak pelatihan dan meluaskan penerapan pekerjaan yang berhubungan dengan Google Suite agar Dewan Paroki dapat terbiasa dengan pemakaian tersebut, karena jika dilihat dari pengaruh definisi mengenai sikap terhadap niat perilaku penggunaan, dan niat perilaku penggunaan terhadap penggunaan sistem sesungguhnya saling berpengaruh positif. Dengan kata lain dapat disimpulkan bahwa Dewan Paroki Santa Maria Assumpta Klaten memiliki tingkat penerimaan teknologi Google Suite yang cukup terlihat dari niat yang bagus untuk belajar dan menganggap bahwa aplikasi ini bermanfaat bagi kegiatan pelayanan gerejawi mereka, yang dapat dilihat dari pengaruh persepsi kemudahan terhadap persepsi kegunaan yang bernilai positif baik dari generasi Baby Boomers maupun generasi Z. Agar tingkat penerimaan teknologi ini meningkat, disarankan dewan yang memegang keputusan strategis dapat mendorong penggunaan Google Suite secara lebih intens dalam aneka ragam program kerja pastoral.

\section{UCAPAN TERIMA KASIH}

Ucapan terima kasih diberikan kepada Dewan Paroki Santa Maria Assumpta Klaten selaku mitra pengabdian masyarakat, juga kepada Lembaga Penelitian dan Pengabdian Masyarakat Universitas Kristen Duta Wacana Yogyakarta yang telah memberikan pendanaan.

\section{DAFTAR PUSTAKA}

Biggs, S. 2007. Thinking about generations: Conceptual positions and policy implications. Journal of Social Issues, 695-711.

Davis, F. D. 1989. Perceived Usefulness, Perceived Ease of Use, and User Acceptance of Information Technology. MIS Quarterly, 319-340.

Setiawan, D. A. 2018. Analisis Penerimaan (Acceptance) Android dan iOS dengan Teknologi Acceptance Model pada Dosen UKDW Yogyakarta. Yogyakarta: Perpustakaan UKDW.

Widiatmoko, P., Chrisantyo, L., \& Dewi, C. N. 2017. DWCU Faculty Membes' Acceptance Toward Learning Management System.

Yuadi, I. 2009. Analisis Technology Acceptance Model Terhadap Perpustakaan Digital dengan Structural Equation Modelling. Departemen Ilmu Informasi dan Perpustakaan UNAIR 